\section{Increasing vulnerability to floods in new development areas: evidence from Ho Chi Minh City}

\section{Increasing vulnerability to floods}

Department of Urban Planning, University of Architecture of Ho Chi Minh City, Ho Chi Minh City, Vietnam and School of Geography, Earth and Environment Sciences, University of Birmingham, Birmingham, UK

Lee Chapman

School of Geography, Earth and Environment Sciences, University of Birmingham, Birmingham, UK

Miles Tight

School of Civil Engineering, University of Birmingham, Birmingham, UK

Phan N. Linh

Department of Urban Planning, University of Architecture of Ho Chi Minh City, Ho Chi Minh City, Vietnam, and

Le V. Thuong

Southern Institute for Spatial Planning of Vietnam, Ho Chi Minh City, Vietnam
Received 6 December 2016 Revised 1 April 2017 Accepted 8 May 2017

\begin{abstract}
Purpose - Flooding is an emerging problem in Ho Chi Minh City (HCMC), Vietnam, and is fast becoming a major barrier to its ongoing development. While flooding is presently of nuisance value, there is a growing concern that a combination of rapid urban expansion and climate changes will significantly exacerbate the problem. There has been a trend of population being rapidly accommodated in new urban areas, which are considered highly vulnerable to floods, while the development strategy by the local government still attracts more property investments into the three new districts on the right side of Saigon River. This paper aims to discuss the increase in the number of residences vulnerable to flooding, to underline the need for more appropriate future spatial development. For the vision, an application of compact and resilient theories to strategic planning and management of this city is proposed to reduce vulnerability. This paper also highlights the need to better understand growing vulnerability to floods related to urban expansion over lowlying former wetlands and the more important role of planning spatial development accompanied with transportation investment which can contribute to flooding resilience.
\end{abstract}

Design/methodology/approach - This research uses combined-methods geographical information system (GIS) analysis based on secondary data of flood records, population distributions, property development (with the details of 270 housing projects compiled as part of this research) and flooding

(C) Phan N. Duy, Lee Chapman, Miles Tight, Phan N. Linh and Le V. Thuong. Published by Emerald Publishing Limited. This article is published under the Creative Commons Attribution (CC BY 4.0) licence. Anyone may reproduce, distribute, translate and create derivative works of this article (for both commercial \& non-commercial purposes), subject to full attribution to the original publication and authors. The full terms of this licence may be seen at http://creativecommons.org/licences/by/4.0/ legalcode 
IJCCSM 10,1

simulation. This allows an integrated approach to the theories of urban resilience and compactness to discuss the implication of spatial planning and management in relevance to flooding vulnerability.

Findings - The flooding situation in HCMC is an evidence of inappropriate urban expansion leading to increase in flooding vulnerability. Although climate change impacts are obvious, the rapid population growth and associated accommodation development are believed to be the key cause which has not been solved. It was found that the three new emerging districts (District 2, 9 and ThuDuc) are highly vulnerable to floods, but the local government still implements the plan for attracted investments in housing without an integrated flooding management. This is also in line with the development pattern of many coastal cities in Southeast Asia, as economic development can be seen as a driving factor.

Research limitations/implications - The data of property development are diversified from different sources which have been compiled by this research from the basic map of housing investments from a governmental body, the Department of Construction. The number of projects was limited to 270 per over 500 projects, but this still sufficiently supports the evidence of increasing accommodation in new development districts.

Practical implications - HCMC needs neater strategies for planning and management of spatial development to minimize the areas vulnerable to floods: creating more compact spaces in the central areas (Zone 1) protected by the current flooding management system, and offering more resilient spaces for new development areas (Zone 2), by improving the resilience of transportation system. Nevertheless, a similar combination of compact spaces and resilient spaces in emerging districts could also be incorporated into the existing developments, and sustainable drainage systems or underground water storage in buildings could also be included in the design to compensate for the former wetlands lost.

Social implications - This paper highlights the need to better understand growing vulnerability to floods related to urban expansion over low-lying former wetlands and emphasizes the more important role of planning spatial development accompanied with transportation investment which can contribute to flooding resilience. Coastal cities in southeast countries need to utilize the former-land, whereas feasibility of new land for urban expansion needs to be thoroughly considered under risk of natural disasters.

Originality/value - A combination of compact spaces with improved urban resilience is an alternative approach to decrease the flooding risk beyond that of traditional resistant systems and underlines the increasingly important role of urban planning and management to combat the future impacts of floods.

Keywords Resilience, Compact city, Flooding vulnerability, Spatial planning and management, Urban expansion

Paper type Research paper

\section{Introduction}

Over 50 per cent of the world's population now lives in urban areas (United Nations - UN, 2014). Growth can be traced back to the nineteenth century where economic drivers provided an impulse for urban expansion as a direct impact of industrialism (Hall and Jones, 2011): a trend that has continued to the present day. In 2010, 167 cities across the world had over 7,50,000 citizens, a result of a 10- to 20-fold increase in population since 1960 (United Nations - UN, 2012). However, as cities continue to grow, the development pressures of new urban areas create an increased concentration of people and assets with a greater potential for devastation from natural disasters. A growing imbalance between the natural and human environment has led to higher risks of floods in major cities (Cigler, 2007). This problem appears to be particularly acute in low gross domestic product countries, as many cities have experienced uncontrolled urban enlargement on low-lying lands. Based on an investigation of 90 cities worldwide, Angel et al. (2005) projected that the built-up areas will increase from 2,00,000 $\mathrm{km}^{2}$ in 2010 to $6,00,000 \mathrm{~km}^{2}$ by 2030 in developing-country cities. Dasgupta et al. (2012) stated that coastal wetlands, which are natural barriers to coastal flooding, have been gradually lost to the process of urban expansion in 76 developing countries, of which "Vietnam is by far the most vulnerable country with close to 65 per cent of its freshwater marshes at risk". Linked to this, Dutta (2011) emphasizes the abnormal 
frequency of flood occurrence in Asian countries, where several cities have faced rapid expansion but owing to a changing climate are now at higher risks of flooding incidents (examples include Bangkok, Manila and Ho Chi Minh City: Asia Development Bank - ADB, 2010).

Ho Chi Minh City (HCMC), a coastal city of Vietnam, is considered to be particularly vulnerable to climate change (World Bank - WB, 2010). It is one of 20 port cities worldwide that have been identified as having both a high rate of population growth and a large number of assets projected to be exposed to sea level rise by 2070 (Nicholls, 2011). In parallel with economic development, despite progressive investments into flood protection system, the frequency and severity of floods have become more significant. The city actually rarely experienced floods until the 1960s (Hong, 2011), but now more than 50 per cent of the urban area of HCMC is affected by regular floods (Asia Development Bank - ADB, 2010). From 2010 to 2015, the Steering Center of the Urban Flood Control Program of HCMC (SCFC) has catalogued 980 inundations which not only endanger citizens but also act as a barrier to the economic prospects of the city. While present flooding in HCMC is frequent, it is presently more of nuisance value causing low level, but widespread, disruption; however, there are concerns that HCMC could begin to experience "extreme" flooding, such as that seen in Bangkok in 2011, if there remains a lack of an effective planning strategy for the urban spatial enlargement (Phi, 2013). Future scenarios indicate that flood-prone areas in HCMC are projected to increase and cover 49 per cent of the built-up area by 2025 , if the $2.0 \mathrm{~m}$ water level is reached (Storch and Downes, 2011), and to 71 per cent by 2050 in case of a combined flood (Asia Development Bank - ADB, 2010). These have resulted in divergent opinions on the link between flooding situation and urban planning and management. Given these views and the rapid expansion of $\mathrm{HCMC}$, this paper investigates flooding vulnerability in relation to the spatial enlargement, particularly in new development areas close to Saigon River.

\section{Ho Chi Minh City: a coastal city increasingly vulnerable to floods}

As an emerging coastal mega-city, the population of HCMC increased from 3.5 million in 1976 to 8.2 million in 2015 (General Statistic Office of Vietnam - GSOV, 2015), but the actual number of people (including unregistered migrants) is now estimated to be nearly 10 million (Asia Development Bank - ADB, 2010). With the current territory of 2,095 $\mathrm{km}^{2}$, the city consists of three zones (Figure 1):

(1) Zone 1-13 central districts including the "old-town" (partly located in District 1 and 5);

(2) Zone 2-6 new development districts where there have been many new residential developments; and

(3) Zone 3-5 suburban districts which used to be the rural land in the early stage.

The growth of HCMC can be attributed to its location as a port city on river basin, attracting a large amount of labor as the driving factor for economic development, but this now provides some disadvantages related to the characteristics of geography and topography. Located $50 \mathrm{~km}$ from the Southeast Asia sea, it is considered one of the three "hot-spots" in this region which is vulnerable to climate changes such as sea level rise (World Bank - WB, 2010; Asia Development Bank - ADB, 2010). Owing to the location on a low-lying coastal plain, 40-45 per cent of land of HCMC is elevated from 0 to $1 \mathrm{~m}$ from sea level (Asia Development Bank - ADB, 2010) and more than 50 per cent of land of HCMC is under $1.5 \mathrm{~m}$ from sea level (Thinh et al., 2009). Along with a process of spatial expansion, the old-town (the core-part of District 1, Zone 1) is found on relatively high-land, but almost all new giant 


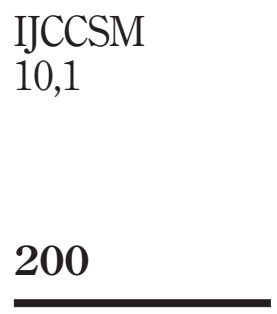

Figure 1.

Urban zones layered over topography

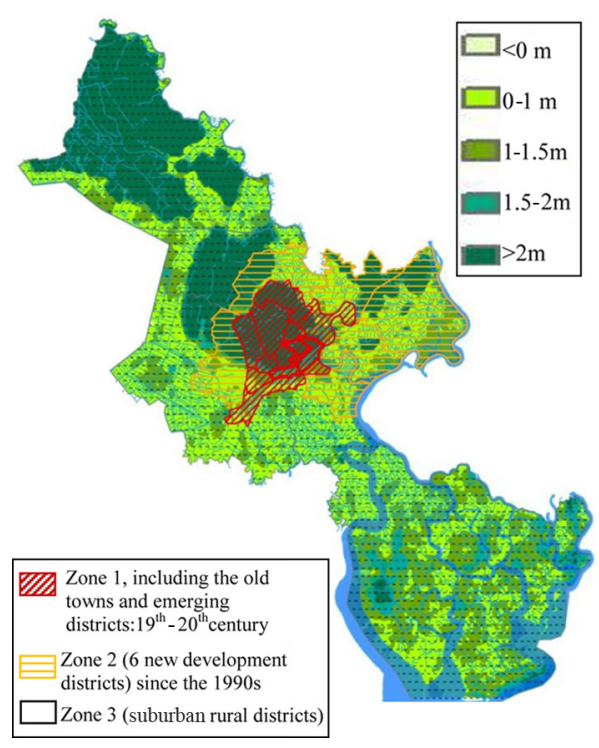

developments in Zone 2, such as PhuMyHung (District 7) and ThuThiem (District 2), are built on areas with a higher risk of flooding owing to the low-lying nature of peripheral areas earmarked for development. The vulnerability of flooding in HCMC is assessed in this paper by using a geographical information system (GIS) approach. The analysis contains population changes, land occupation for property investments and flood impact simulations to ascertain to what extent urban development is leading to an increase in vulnerability to floods in new development areas. Based on this analysis, an extrapolation of the trend of urban settlement over vulnerable areas to floods, especially in three emerging districts on the eastern side of Saigon River, is needed to examine the future implications for the city. Finally, through the vision for HCMC, the paper will discuss issues related to a potential link between the theories of compact city and resilient city to propose a strategy of urban planning and management as the long-term solution to flooding.

\subsection{Urban expansion and flooding impacts}

Since the early beginnings in the seventeenth century, the original town covered about 5 $\mathrm{km}^{2}$ with a population of around 2,00,000 people, the first rampart named GiaDinh had been built on (locally) a high-land (4-6 m), presently located in District 1 . In the nineteenth century, Saigon, the old name of HCMC, was established as the most modern city in Southeast Asia in the light of a development plan to expand the city to $25 \mathrm{~km}^{2}$, with a view to accommodating 5,00,000 people. Until the end of twentieth century, the built-up area was limited to the left of Saigon River.

By the beginning of the twenty-first century, widespread and uncontrolled urban enlargement of HCMC was occurring on previously rural land. Since the establishment of six new districts in 1997, there was a shifting trend of dwellers moving from the old center to the new suburbs, but such changes in population distribution had not adequately considered the vulnerability to floods (Storch and Downes, 2011). In fact many of the new development areas close to Saigon River were vulnerable to fluvial floods; Thinh et al. (2009) reported five 
districts affected by tides in combination with heavy rains in 2008. Some of these, such as BinhThanh and District 2 in Zone 2, were more susceptible to floods because of the higher rate of urbanization resulting in high-density residences ( $\mathrm{Tu}, 2010)$. In the 2000s, this is also evident with the high-rate of construction across emerging districts (e.g. 2, 6, 7, 8, 12 and Binh-Tan from 1989 to 2002: Viet, 2008). An illustration of this is the rapid development of PhuMyHung (409 ha, in District 7) and ThuThiem (657 ha, in District 2), which are the two ignition projects of a larger process containing a vast number of property developments. These projects not only trigger the enlargement of urban areas accompanied with higher concentration of people and assets but also negatively affect indigenous hydrological systems, including green spaces and water bodies. Indeed, there was a rise in the area of impermeable surface versus a decrease in areas of water from 1985 to 2010 (Phi, 2013) [Figure 2(a)], and it appears that the link between new development and flood frequency is striking.

On the other hand, HCMC has also been exposed to noticeable climatic changes related to precipitation regimes and water levels in Saigon River. For example, there is a trend of a higher frequency of heavy rains (more than $50 \mathrm{~mm}$ ) from 1999 to 2009 (Phi, 2013). However, upstream rainfall is only an exacerbating factor to flooding instead fluvial floods from the intense monsoon rainfall is more significant (Asia Development Bank - ADB, 2010). The observation data showed the increase in water levels at the PhuAn station (within Saigon River), where the levels were higher than those at the VungTau station (in the sea mouth) from 2010 to 2015 (SRHC, 2010-2015). This implies that the riverine level of HCMC has increased not only by global (sea level rise) SLR but also by other reasons related to urbanization during development such as reduction in area of agriculture and water and land subsidence by high density of construction (Phi, 2013):

(1) Overall, the footprint of the city has rapidly changed since the 1990s with the presence of new development districts and "rural districts" in peripheral areas (particularly to the east and southeast). The development process has seen the city extend its boundary across the main water bodies, Saigon River in the East and ThiNghe-Te channel in the South to accommodate the rapid population growth. Consequently, there has been depletion in area of wetlands which are essential for natural protection for the city. These lands had previously acted as a natural buffer with a large network of water bodies, including rivers, canals and channels, but now hard surfaces are further influencing resilience of the broader city to flooding. While climate changes such as SLR and uncertain precipitation are general factors in HCMC, uncontrolled urbanization is believed to be the dominant factor for increased flooding in HCMC (Hong, 2011; Storch and Downes, 2011; Phi, 2013). This is a challenge for flood management because of dynamic social changes in combination with the uncertain nature of climatic changes.

\subsection{Current flood management}

The master plan for water discharge toward 2020 (since decision 752 by the central government in 2001) identified six zones consisting of the current inner city (about 140 $\mathrm{km}^{2}$ ) and surrounding areas (about $510 \mathrm{~km}^{2}$ ) from which water would be discharged through dedicated channels (Figure 3). A supplementary plan with an expanded area for management (decision 1547) was actioned in 2008 to optimize the water storage capacity of current water bodies of HCMC and to control flash floods from upper regions and upstream water from the main rivers (ibid). According to this plan, the water level of $+1.32 \mathrm{~m}$, has been chosen for following designs, but the highest tides 


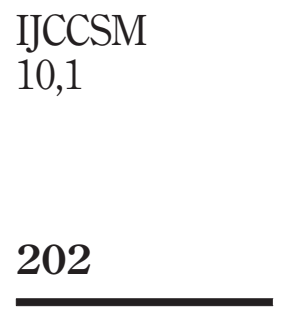

Figure 2.

Changing factors related to floods
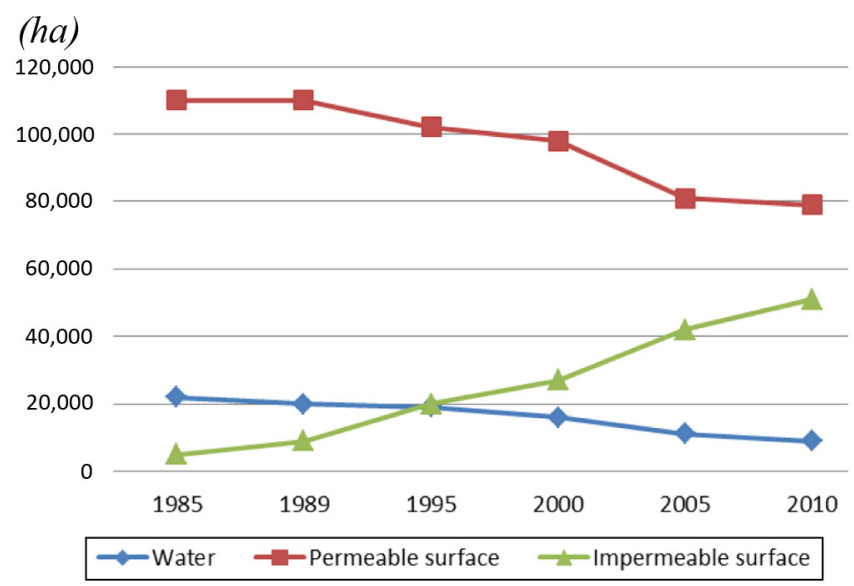

(a)

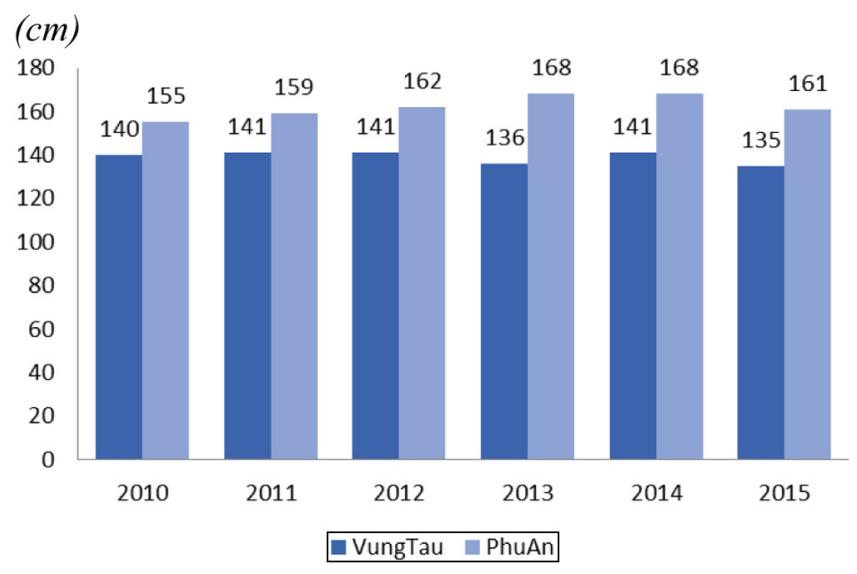

(b)

Notes: (a) Changes in areas of water, permeable surfaces and impermeable surfaces since population growth (Phi, 2013); (b) water levels in comparison between VungTau (East Sea) and PhuAn (SaiGon River) SRHC (2010-2015)

were recently recorded at $+1.68 \mathrm{~m}$ in 2013 and 2014 (Southern Regional Hydro Meteorological Center - SRHC, 2015). Fundamentally, these plans focus on utilization of existing water bodies. The flooding control system mainly consists of sluices and embankment from which the safety range to current thresholds is likely insufficient; this system, once completed by 2020, will not cover the new districts on the right side of Saigon River (Figure 3).

Urgent actions are now required, the city has been accelerating existing projects such as dredging channels, improving drainage systems, building an embankment along the left side of 


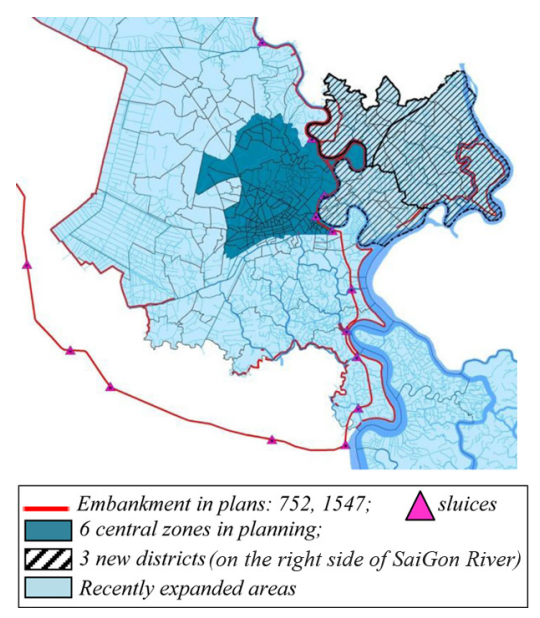

\section{Increasing vulnerability to floods}

203

Figure 3.

Flooding management in zones

Saigon River, constructing of sluices and creation of reservoirs. However, their effectiveness is in question, despite a cost of around US\$1bn, floods still frequently happen in this city. It is argued that the current proposals are just short-term solutions based on engineering structures while the city has not resolved the poor spatial planning (Phuc, in Nguyen, 2015). Long-term flood management ultimately needs to control the rapid urbanization process, especially in new development areas (Storch et al., 2009; Storch and Downes, 2011; Hong, 2011; Phi, 2013). Hence, this paper examines to what extent such process increases flooding vulnerabilities of HCMC, especially in the developing districts on the eastern side of Saigon River.

\section{Data and methodology}

Risks from climate change impacts arise from the interaction between hazard (triggered by an event or trend related to climate change), vulnerability (susceptibility to harm) and exposure (people, assets or ecosystems at risk) (International Panel on Climate Change - IPCC, 2014, p. 36).

In this research, the main method is GIS analysis which is based on secondary data of flood records, population distributions, property development (with the details of 270 housing projects compiled as part of this research) and flooding simulation. These data were made available from institutional bodies in Vietnam and other agencies and are summarized in Table I.

\begin{tabular}{lcl}
\hline Type of data & Available period & Source \\
\hline $\begin{array}{l}\text { Population distribution } \\
\text { Property development }\end{array}$ & $1981-2015$ & $\begin{array}{l}\text { General Statistic Office of Vietnam (GSOV) } \\
\text { Information collected by this research, relied on the } \\
\text { property investment map from Department of Construction } \\
\text { of HCMC (COD) }\end{array}$ \\
Flooding event record & $2010-2015$ & $\begin{array}{l}\text { Steering Center of Flood Control Program of Ho Chi Minh } \\
\text { City (SCFC) } \\
\text { Asia Development Bank - ADB (2010), with the maps of } \\
\text { flooding prepared by ICEM (2009) }\end{array}$ \\
\hline
\end{tabular}

Table I.

Key datasets used for analysis 
IJCCSM

10,1

204

From this analysis, current and future vulnerability can be measured. Vulnerability is defined as the extension of harm which is evaluated by the implications of exposure, susceptibility and resilience under particular conditions (Balica and Wright, 2009; Hufschmidt, 2011; Scheuer et al., 2010; Willroth et al., 2010; Fuchs et al., 2011, cited in Balica et al., 2012, p. 75). There is a need to drill down into the different components of vulnerability (Balica et al., 2012):

- exposure - location of people and other assets in relation to flood prone areas;

- susceptibility - factors influencing degree of impacts such as awareness and preparation of citizens (aided by institutional response); and

- resilience - ability of a city to adapt to floods by re-organizing itself to maintain acceptable levels of function and structure.

In the case of HCMC, flooding vulnerability is defined as the probability of flood impacts in a particular area. Exposure (i.e. increased concentration of people in flood prone areas) is the core factor but susceptibility and resilience can significantly increase or reduce the degree of vulnerability. The susceptibility depends on location and time where and when a flood occurs, whereas resilient capacity can be evaluated through the possibility of evacuation and recovery through the transportation system in case of an extreme flood.

\section{Assessing vulnerability to floods}

\subsection{Exposure}

Alongside with urban expansion, the population growth rate in Zone 2 (6 new development districts) has been extremely high, particularly notable from 2003 onward in contrast to Zone 1 (13 central districts) [Figure 4(a)]. The data of property development showed that the area of land for the housing projects was 725 ha for implementation from 2010 to 2015, and it is predicted to increase by 3,670 ha in 2030. In comparison with Zone 1, such land area was much higher in Zone 2 [Figure 4(b)]. The subsequent GIS analysis (overlaying land occupied by these projects with areas affected by floods) indicates a majority of residential developments located in vulnerable area [ Figure 5(a)], and this trend will continue by 2050 in reference to the extreme flooding scenario [Figure 5(b)]. Such developments are now starting to include more peripheral areas, but these areas are of low elevation and particularly prone to fluvial flooding. Indeed, the record of floods by SCFC supported that there was a rising proportion of number and length of inundation, especially in Zone 2, from 29 per cent in 2010 to 52 per cent in 2015 [Figure 4(c)]. Obviously, there have been an increase in the number of people and their assets exposed to flooding.

\subsection{Susceptibility}

Owing to the characteristics of the tropical weather experienced and its location in the Mekong delta region, HCMC often has high precipitation in annual rainy season (mainly from May to November), while it is also influenced by "semi-diurnal tides" (mainly from September to December), two nearly equal high and low tides a day with a shifting time of about $50 \mathrm{~min}$ on each contiguous day (TEDISouth, 2010). Hence the city is highly susceptible to floods from September to October, when there are more potentially combined effects with heavy rains. The statistics of flooding events by months (SCFC, 2010-2015) support that the highest level and frequency of floods is normally from September to November every year. Furthermore, the impacts are more disruptive if floods happen at peak times (6-8 a.m.; 4-6 p.m.) when urban activities are at their daily peak through physical transportation (mainly on roads). For example, the extreme flood on September 15, 2015, occurred after a heavy and long rain being 


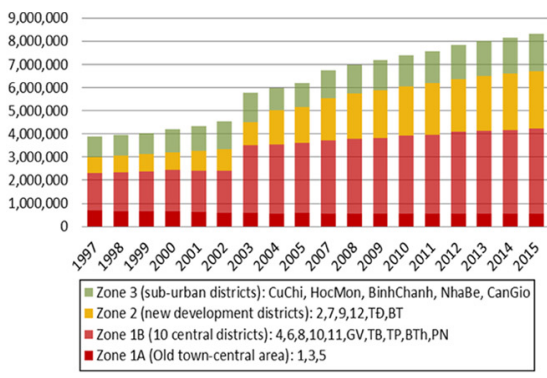

Increasing vulnerability to floods

(a)

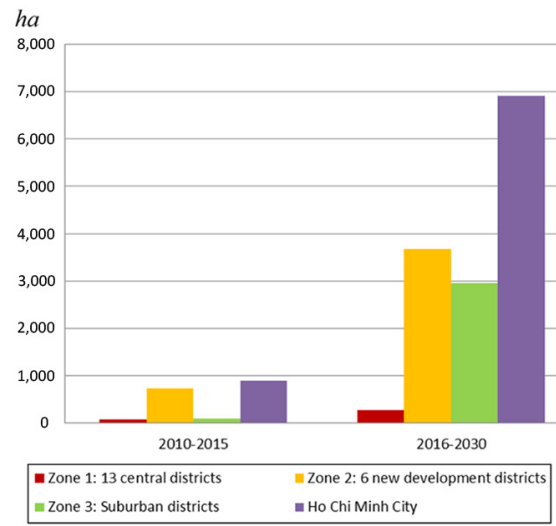

(b)

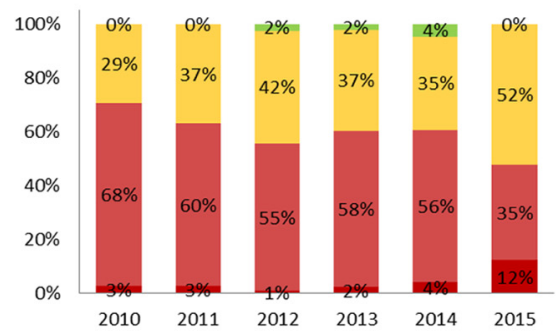

m Zone 3: Rural districts (NhaBe, CanGio, HocMon, CuChi Zone $2: 6$ new districts $(2,7,9,12$, ThuDuc, BinhTan)

- Zone 1B: 10 central districts except old-town $(4,6,8,10$

11, BinhThanh, PhuNhuan, GoVap, TanBinh, TanPhu) - Zone 1A: Old-centers (district 1, 3, 5)

(c)

Notes: (a) Population distribution GSOV (1997-2015); (b) land for housing development from 2010-2030; (c) length and location of roads affected by floods SCFC (2010-2015)

Figure 4. Urban development and flood impacts 
IJCCSM

10,1

206
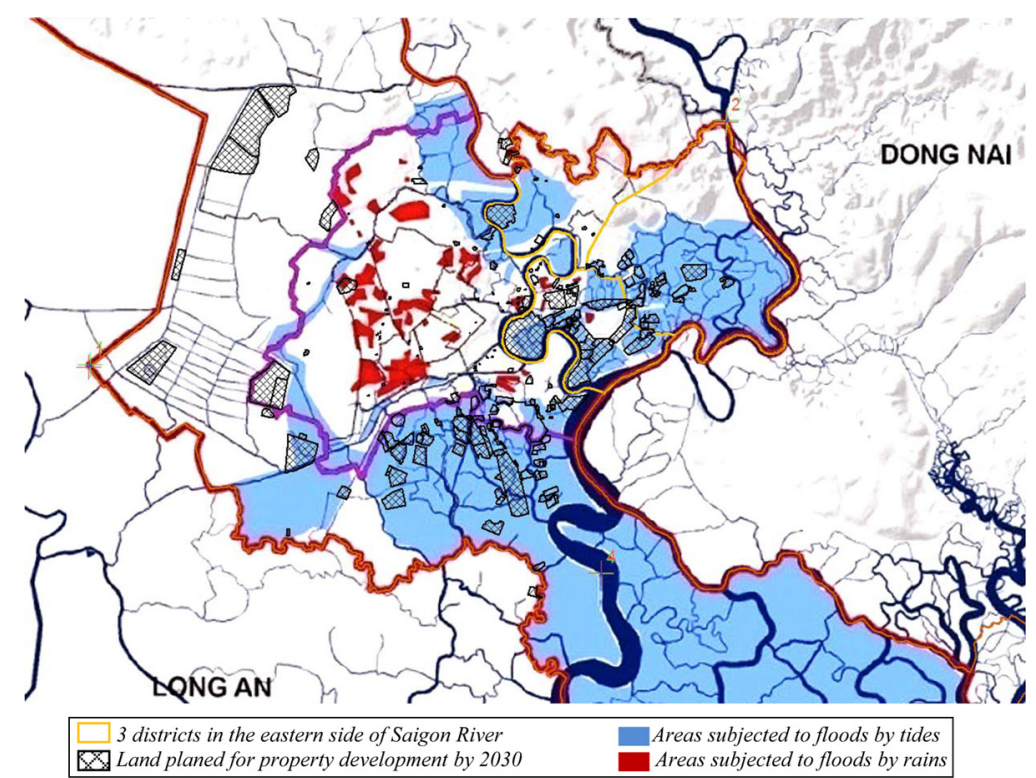

(a)

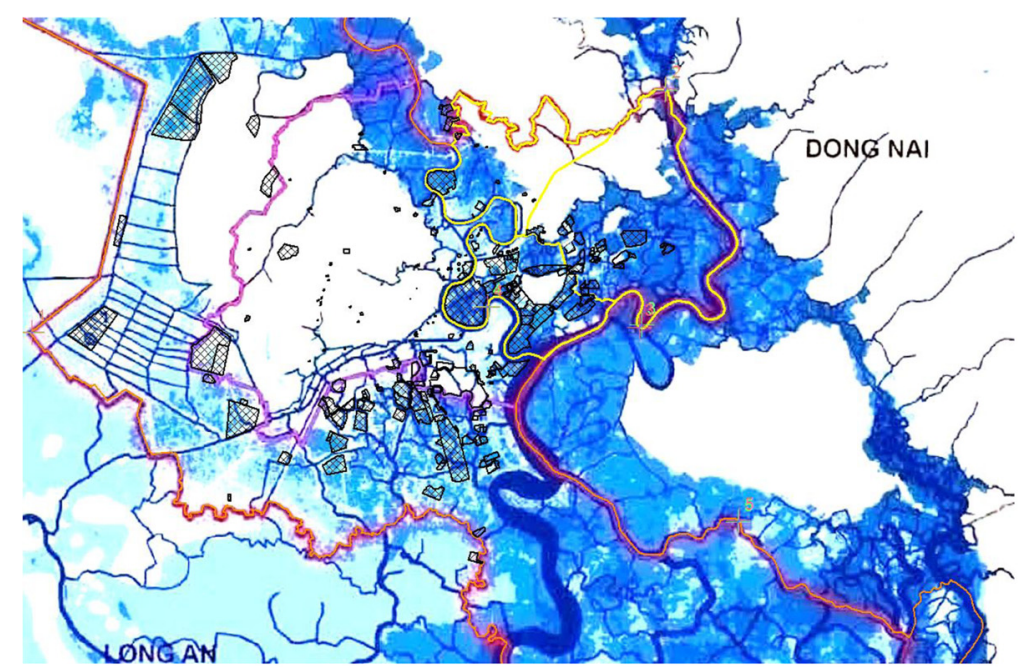

3 districts in the eastern side of Saigon River $\quad$ Flood extent under high emission scenario

(b)
Figure 5.

Property

developments

exposed to floods
Notes: (a) Properties exposed to regular floods; flood map adapted from ICEM (2009); (b) properties exposed to extreme floods under high emission scenario; flood map adapted from ICEM (2009) 
followed by a high tide around 4-6 p.m., resulting in a large-scale effect to urban transportation. In brief, high tides can be seen as the "background/regular factor", heavy rains are the "exacerbated/uncertain factor"; and uncontrolled housing developments is actually the driving factor for increasing people and assets exposed to floods.

\subsection{Resilience}

Urban resilience can help the city to return to normal situation after flooding effects. However, the dependency on flooding control not only influences riverine ecosystems but also increases long-term flood risk (Burby et al., 2000; Smits et al., 2006), and this is not a reliable approach to climatic uncertainties (Zevenbergen and Gersonius, 2007). On the other side, urban resilience can be undermined if natural effects create an obstruction to transportation system because transport network has a vital role in connection between urban physical structures and in maintenance of urban operation. Desouza and Flanery (2013) stated that it is a physical element contributing to key urban resources for resilience. The GIS analysis by this research explores that a large-scale flood, such as the extreme incident in Bangkok, will affect to vulnerable sessions of several roads in HCMC and can divide the city into two parts: the western and the eastern side of Saigon River, regardless of the performance of embankment flood defenses (Figure 3). In particular, this causes an isolation of three development districts (2, 9 and ThuDuc), which have not been covered by the current protection system. As a result, there will be a large number of new residences isolated by floods in these places to which the arteries from the city center are potentially inaccessible. Referring to the high flood on September 15, 2015, many main streets have been obstructed up to $4 \mathrm{~h}$ as the vehicle flows were decelerated before blocked at important nodes such as HangXanh; as a result, many people could not return to their homes in these districts. This provides an example of how the resilience of this city is compromised by floods affecting the transportation network, especially to main routes or nodes/intersections.

By using this approach, the impact of flooding can be analyzed. In the case of HCMC, the highest risk is the combination of inner floods by heavy rains with tidal floods. The flooding vulnerability is generated by the increase in number of people and assets exposed to floods in new development districts, Zone 2. This paper highlights the areas of recent property developments in Districts 2, 9 and ThuDuc, which are believed to be the most vulnerable districts to flooding effects. This requires an improved consideration of resilience for the new residences in these areas rather than just short-term solutions based on traditional flood defense.

\section{Discussion}

\subsection{Impact of future changes (climatic and social) in Ho Chi Minh City}

In line with climate change impacts related to SLR and uncertain precipitation, HCMC has continually been improving its flooding management, but the continuing mismatch between the current planning, implementation and the volatility of climatic and social factors remains considerable. Several flood defense projects, mainly deployed in central areas, are still in progress but the built-up area has rapidly extended beyond the zones identified for protection. Furthermore, there are concerns that the design and construction of city-scale protection systems are obsolete because of the many changes in precipitation and river levels. An illustration of this is the proposed elevation of the river bank system $(+2.5 \mathrm{~m}$, according to the plan 1547 mentioned in Section 3.2): when completed, it will be just $82 \mathrm{~cm}$ over the recently maximum tides at $+1.68 \mathrm{~m}$ recorded in 2013 and 2014, but the SLR to Vietnam is projected to increase by 75-100 cm by 2100 (Asia Development Bank - ADB, 2010; Ministry of Natural Resources and Environment of Vietnam - MNRE, 2012), with the increasing rate of water level 
IJCCSM

10,1

at rivers in HCMC will be higher as compared to the sea level (Phi, 2013). According to the hydrological report by the Southern Regional Hydro-meteorological Center of Vietnam-SRHC, after 34 years, the average increase in maximum water at VamKenh station (at VungTau estuary) versus PhuAn station (on Saigon River) is 13.2 and $37.8 \mathrm{~cm}$, respectively (the five years period 1981-1985 compared to 2011-2015). Besides, the extreme weather, such as heavy rains, has been challenging the existing capacity of the urban infrastructure. In 2016, there was a rainfall peak at $208 \mathrm{~mm}$ (during $2 \mathrm{~h}$ ), whereas the current drainage system has been designed for rains under $100 \mathrm{~mm}$ (Steering Center of Flood Control Program of Ho Chi Minh City - SCFC, 2016). These imply that the current flood management plans are lagging behind the changes of both climatic and human factors. It is impractical to deliver a large budget to new defences which mainly protect the central areas, but the majority of citizens have been highly accommodating in new developing areas. In the future, the threshold of defenses to floods, as the safety range, will be exceeded by climate changes, while the city has been experiencing more new residences on flood plain unless appropriate adjustments to spatial development. Fundamentally, this paper criticizes the fact that uncontrolled and subjective plan for urbanization depended on a hard-engineered protection system. This, when coupled with climate changes, will ensure the city is increasingly vulnerable to floods and is in urgent need of a long-term and comprehensive strategy, from theory to practice.

\subsection{Visions for Ho Chi Minh City: resilience and compactness}

Like many cities across the world, the original urban areas of HCMC have a situational advantage, e.g. higher elevation, that has traditionally made them resistant to floods, but the vulnerability increases as more and more peripheral lands are built-up. The speed of the development is crucial here. Flood management policy can be slow, and there is often long duration required to get a protection system from planning to implementation, whereas urbanization fundamentally follows the free-market of property development. This challenges any urban physical infrastructure dealing with uncertainties while hard engineered solutions can often be insufficient.

Assuming urban development is inevitable, increasing compactness in terms of spatial planning and management is potentially the answer for a city to reduce vulnerability to floods. A compact city, which adheres to the desirability of sustainable development advocated by the European Community since the 1990s (Commission of the European Community-CEC, 1990), is still contemporarily supported by scholars who emphasize the energy efficiency with the promotion of "intensification of the use of space in the city" (Elkin et al., 1991, p. 16), viability of amenity and facility for social sustainability (Haughton and Hunter, 1994) and "offer the maximum scope for effective traffic reduction" (McLaren, 1992, p. 281). In several cities in Organisation for Economic Co-operation and Development (OECD) countries, its potential success has been demonstrated in meeting urban needs of public transport and accessibility to local services, while lessening environmental impacts (Matsumoto, 2012). More broadly, this paper focuses on reducing impacts in urban areas prone to floods, by considering the role of the vertical dimension as opposed to just centripetal urbanization leading to widespread construction on floodplains. Centralized, compact spaces could be deployed from urban to building scale to urban scale. "Urban flood risks should be proactively managed through resilience, taking advantage of interventions at different spatial levels" (Zevenbergen et al., 2008). Subsequently, urban public space should be improved and opened for "absorbable surface" such as green areas, and there is a need of maximized function within buildings in terms of architectural design, e.g. optimized height, interconnected corridors, storage spaces for water. Transportation structures are not only the interlinks between civil buildings and urban spaces but also an incentive for 
improving adaptation to regular floods and a supporting element for resilience to extreme floods.

Despite the claimed advantages, the compactness theory has been debated in relevance to the different context of application (e.g. Europe, UK, US or AU) and the quality of living environment. Decentralization has remained the trend in urban development (Breheny and Rookwood, 1993), while centralization (compactness) is a choice for cities targeting sustainable development (Thomas and Cousin, 1996). As a balance, a compromising stance reconciles sustainability with controlled development (Jenks et al., 1996). For example, urban decentralized areas can contain several compacted settlements interlinked by public transport (Haughton and Hunter, 1994), walking and cycling are appropriate to encourage social interaction between different residences (Elkin et al., 1991) and health benefits and lower congestion (Miles et al., in Chapman and Ryley, 2012). Additionally, these routes can become emergency evacuation routes in the case of an extreme flood if incorporated into defense schemes. Hence, new developments with compact spaces on advantage lands (e.g. high elevation, distance construction from flooding risk factors) can be both less exposed to floods as a promising solution to enhance urban resilience.

In the case of HCMC, buildings should be built in old-town areas to allow intensification in those areas protected by current flooding defense, whereas the new development areas should be designed such that there are more open spaces for water absorption. In coordination, "vertical transportation" in complex buildings will be an appropriate solution to uncertain floods, whereas "horizontal transportation" will ensure the contiguous connections between different concentrated areas. On the other hand, once commuting distance between different urban areas can be reduced, it is more possible for emergency evacuation through a resilient transport network, including routes elevated from the ground and flexibly transferable modes. Meanwhile, existing emergency exits in buildings should connect to these priority routes providing targeted evacuation points.

\section{Conclusion}

The flooding situation of HCMC is an evidence of inappropriate urban expansion leading to increase in flooding vulnerability. Although climate change impacts are obvious, the rapid population growth and associated accommodation development are believed to be the key cause which has not been solved. This research found that the three new emerging districts (District 2, 9 and ThuDuc) are highly vulnerable to floods in the near future, but the local government still implements the plan for attracted investments in housing without a reference to the flood impacts evaluated by existing researches. This not only exposes more citizens and their assets to floods but also exacerbates the flooding situation of surrounding areas. Furthermore, the existing flood management relies on hard-engineered systems, and soft solutions, such as green-spaces for water absorption and reverting natural water ways and reservoirs integrated in parks for water storage have not been cooperated and deployed in practice. This also undermines urban resilience to extreme floods in the long term. Therefore, the city needs neater strategies for planning and management of spatial development to minimize the areas vulnerable to floods:

- creating more compact spaces in the central areas (Zone 1) protected by the current flooding management system; and

- offering more resilient spaces for new development areas (Zone 2), by improving resilience of transportation system.

Nevertheless, a similar combination of compact spaces and resilient spaces in emerging districts could also be incorporated into the existing developments, while sustainable
Increasing vulnerability to floods 
IJCCSM 10,1

drainage systems or underground water storage in buildings could also be included in the design to compensate for the former wetlands lost.

The findings in HCMC can be extended to the developing pattern of many coastal cities in Southeast Asia. For almost all these countries, economic development can be seen as a driving factor, expanding the cities despite the obvious disadvantages of topography and the negative interactions to the existing natural environment. Natural disasters, including floods, are likely to exceed present day predictions despite the improvement of forecasting technology. Therefore, these cities need to rethink how they can use the most naturally flood-resistant land (i.e. compact approach) to improve the overall resilience of new developments. As a contribution to urban planning and management in practice, this paper underlines the increasingly important role of urban planning and management to combat the future impacts of floods in coastal-mega cities. Furthermore, a combination of the compact city and resilient city, there is a potential topic for further research in planning and management of urban spatial development adaptive to flooding.

\section{References}

Angel, S., Sheppard, S.C. and Civco, D.L. (2005), The Dynamics of Urban Expansion, Transport and Urban Development Department, World Bank, Washington, DC.

Asia Development Bank - ADB (2010), Ho Chi Minh City Adaptation to Climate Change, ADB, Philippines, ISBN: 978-971-561-893-9.

Balica, S.F. and Wright, N.G. (2009), "A network of knowledge on applying an indicator-based methodology for minimizing flood vulnerability”, Hydrol Process, Vol. 23 No. 20, pp. 2983-2986, doi: 10.1002/hyp.7424.

Balica, S.F., Wright, N.G. and Van deu Meulen, F. (2012), "A flood vulnerability index for coastal cities and its use in assessing climate change impacts", Natural Hazards, Vol. 64 No. 1, pp. 73-105, doi: 10.1007/s11069-012-0234-1.

Breheny, M. and Rookwood, R. (1993), "Planning the sustainable city region”, in Blowers, A. (Ed.), Planning for a Sustainable Environment, a Report by the Town and Country Planning Association, Earthscan, London.

Burby, R.J., Deyle, R.E., Godschalk, D.R. and Olshansky, R.B. (2000), "Creating hazard resilient communities through land-use planning", Natural Hazards Review, Vol. 1 No. 2, pp. 99-106, doi: 10.1061/(ASCE)1527-6988 (2000)1:2(99).

Chapman, L. and Ryley, T. (2012), Transport and Climate Change, Emerald Group, London, Vol. 2, ISBN: 978-1-78052-440-5.

Cigler, B.A. (2007), The "Big Questions" of Katrina and the 2005 Great Flood of New Orleans, Pennsylvania State University, Harrisburg.

Commission of the European Community-CEC (1990), Green Paper on the Urban Environment, CEC, Brussels, EUR $12902 \mathrm{EN}$.

Dasgupta, S., Blankespoor, B. and Laplante, B. (2012), "Sea-level rise and coastal wetlands", Policy Research Working Paper (WPS6277), World Bank.

Desouza, K.C. and Flanery, T.H. (2013), "Designing, planning, and managing resilient cities: a conceptual framework", Cities, Vol. 35, pp. 89-99.Elsevier, doi: 10.1016/j.cities.2013.06.003.

Dutta, D. (2011), "An integrated tool for assessment of flood vulnerability of coastal cities to sea-level rise and potential socio- economic impacts: a case study in Bangkok - Thailand", Hydrological Sciences Journal, Vol. 56 No. 5, pp. 805-823, doi: 10.1080/02626667.2011.585611.

Elkin, T., McLaren, D. and Hillman, M. (1991), Reviving the City: Towards Sustainable Urban Development, Friends of The Earth, London. 
Fuchs, S., Kuhlicke, C. and Meyer, V. (2011), "Editorial for the special issue: vulnerability to natural hazards - the challenge of integration”, Natural Hazards, Vol. 58 No. 2, pp. 609-619, doi: 10.1007/ s11069-011-9825-5.

General Statistic Office of Vietnam - GSOV (2015), "Population of Ho Chi Minh from 1986-2015”.

Hall, P. and Jones, M.T. (2011), Urban and Regional Planning, 5th ed., Rutledge, London, ISBN: 978-0-415-56654-4.

Haughton, G. and Hunter, C. (1994), Sustainable Cities, Jessica Kingsley Publishers, London.

Hong, T.D. (2011), "Flooding in Saigon", (translated from Vietnamese), available at: http:// myweb.tiscali.co.uk/hbtdp/_private/Sai\%20Gon \%20ngap \%20lut\%20-\%20Tran \%20Dang $\% 20$ Hong.htm

Hufschmidt, G. (2011), "A comparative analysis of several vulnerability concepts”, Natural Hazards, Vol. 58 No. 2, pp. 621-643, doi: 10.1007/S11069-011-9823-7.

International Center for Environmental Management ICEM (2009), "Ho Chi Minh City adaptation to climate change", Volume 2-Main Report, ICEM - ADB.

International Panel on Climate Change - IPCC (2014), "Climate change 2014: synthesis report", Contribution of Working Groups I, II and III to the Fifth Assessment Report of the Intergovernmental Panel on Climate Change, Core Writing Team, R.K. Pachauri and L.A. Meyer (Eds.), IPCC, Geneva, p. 151.

Jenks, M., Burton, E. and Williams, K. (1996), The Compact City: A Sustainable Urban Form?, E \& FN Spon, London, ISBN 0419213007.

McLaren, D.P. (1992), “Compact or dispersed? Dilutions is no solution”, in Willis, K.G., Turner, R.K. and Bateman, I.J (Eds), Urban Planning and Management, Edward Elgar Publishing, Cheltenham, pp. 43-59.

Matsumoto, T. (2012), "Compact city policies: a comparative assessment", OECD available at: www. oecd.org/greengrowth/compact-city-policies-9789264167865-en.htm

Ministry of Natural Resources and Environment of Vietnam - MNRE (2012), Climate Change Scenarios for Vietnam, Vietnam Publishing House of Natural Resources, Environment and Cartography, Hanoi.

Nguyen, H. (2015), "Ho Chi Minh City needs about VND 100,000 billion for flood defense (translated from Vietnamese)", VNEXpress, available at: http://vnexpress.net/tin-tuc/thoi-su/tp-hcm-can100-000-ty-dong-de-chong-ngap-3281838.html (accessed 19 April 2017).

Nicholls, R.J. (2011), "A global ranking of port cities with high exposure to climate extremes", Climatic Change, Vol. 104, pp. 89-111, doi: 10.1007/s10584-010-9977-4.

Phi, H.L. (2013), "Urban flood in Ho Chi Minh City: causes and management strategy", Vietnamese Journal of Construction Planning, Vol. 63, pp. 26-29, Hanoi. (In Vietnamese).

Scheuer, S., Haase, D. and Meyer, V. (2010), "Exploring multi-criteria flood vulnerability by integrating economic, social and ecological dimensions of flood risk and coping capacity: from a starting point view towards an end point view of vulnerability", Nat Hazards, Vol. 58, pp. 731-751, doi: 10.1007/s11069-010-9666-7.

Smits, A.J.M., Nienhuis, P.H. and Saeijs, H.L.F. (2006), "Changing estuaries, changing views", Hydrobiologia, Vol. 565, pp. 339-355, doi: 10.1007/s10750-005-1924-4.

Southern Regional Hydro - Meteorological Center - SRHC (2015), "Water level and Precipitation Records 2010-2015", (data extracted).

Steering Center of Flood Control Program of Ho Chi Minh City - SCFC (2016), "Flooding reports for the events in 15th September 2015, and in 26th September 2016".

Storch, H. and Downes, N.K. (2011), "A scenario-based approach to assess Ho Chi Minh City urban development strategies against the impact of climate change", Cities, Vol. 28, pp. 517-526, doi: 10.1016/J.CITIES.2011.07.002. 
IJCCSM

10,1

Storch, H., Downes, N., Thinh, N.X., Thamm, H.P., Phi, H.L., Thuc, T., Thuan, N.T.H., Emberger, G., Goedecke, M., Welsch, M. and Schmid, M. (2009), "Adaptation planning framework to climate change for the urban area of Ho Chi Minh City, Vietnam”, Fifth Urban Research Symposium 2009, World Bank, available at: http://siteresources.worldbank.org/INTURBANDEVELOPMENT/ Resources/336387-1256566800920/6505269-1268260567624/Storch.pdf

TEDISouth (2010), "Transportation planning for Ho Chi Minh City by 2020".

Thinh, N.X., Bräuer, A. and Teucher, V. (2009), "Introduction into work package urban flooding of the BMBF megacity research project Ho Chi Minh City", Environmental Informatics and Industrial Environmental Protection: Concepts, Methods and Tools, Shaker Verlag, Berlin, ISBN: 978-3-8322-8397-1.

Thomas, L. and Cousin, W. (1996), "The compact city: a successful, desirable and achievable urban form?", Jenks, M., Burton, E. and Williams, K. (Eds), The Compact City: A Sustainable Urban Form?, E \& FN Spon, London, pp. 53-65, ISBN 0419213007.

Tu, T.T. (2010), “Adaptation to flood risks in Ho Chi Minh City, Vietnam”, International Journal of Climate Change Strategies and Management, Vol. 3 No. 1, pp. 61-67, doi: 10.1108/ 17568691111107943.

United Nations - UN (2012), "Population division”, World Urbanisation Prospects: The 2011 Revision, Department of Economic and Social Affairs, United Nations, New York.

United Nations - UN (2014), World Urbanization Prospects - Highlights, UN, New York, NY.

Viet, L.V. (2008), "The urbanization and Climate Changes in Ho Chi Minh City", Proceedings of the 10th Conference of Res. Inst. of Hydrology and Environment, pp. 369-375.

Willroth, P., Revilla Diez, J. and Aruntai, N. (2010), "Modeling the economic vulnerability of households in the Phang-Nga province (Thailand) to natural disasters", Nat Hazards, Vol. 58, pp. 753-769, doi: 10.1007/s11069-010-9635-1.

World Bank - WB (2010), Climate Risks and Adaptation in Asian Coastal Megacities: A Synthesis Report, The World Bank, Washington, DC.

Zevenbergen, C. and Gersonius, B. (2007), "Challenges in urban flood management", in Ashley, R., Garvin, S., Pasche, E., Vassilopoulos, A. and Zevenbergen (Eds), Advances in Urban Flood Management, Taylor \& Francis, New York, NY, pp. 1-11, doi: 10.1201/9780203945988.

Zevenbergen, C., Veerbeek, W., Gersonius, B. and VanHerk, S. (2008), "Challenges in UMF - travelling across spatial and temporal scales", Flood Risk Management, Vol. 1, pp. 81-88, Blackwell Publishing Ltd.

\section{Corresponding author}

Phan N.Duy can be contacted at: duyadm@gmail.com and duy.phannhut@uah.edu.vn

For instructions on how to order reprints of this article, please visit our website:

www.emeraldgrouppublishing.com/licensing/reprints.htm

Or contact us for further details: permissions@emeraldinsight.com 